\title{
Ultrasound in the Diagnosis of Twin-to-Twin Transfusion Syndrome - a Preliminary Report
}

\author{
M. Ropacka, W. Markwitz, W. Ginda, G. H. Bręborowicz \\ Department of Perinatology and Gynecology, University School of Medical Sciences, \\ Poznań, Poland
}

Objective. The aim of this study was to show the diagnostic possibilities of ultrasound in twin-to-twin transfusion syndrome (TTTS), to demonstrate its usefulness in cases of hemoglobin difference $<5 \mathrm{~g} / \mathrm{dL}$ in neonates as well as in cases complicated by intrauterine death of one or both twins.

Study design. The study included 4 pairs of twins. In two cases 3 fetuses died in utero. In the other two the hemoglobin difference in newborn infants was $<5 \mathrm{~g} / \mathrm{dL}$. The ultrasound examination, evaluating the fetal anatomy and biometry, amniotic fluid volume, placentation, was performed. The special attention was paid to polyhydramnios/oligohydramnios, discordant fetal growth (fetal weight, abdominal circumference), the presence of fetal hydrops, ascites, pericardial effusion. Doppler blood flow velocimetry has been done in umbilical vessels, middle cerebral artery. The data was compared with normal reference values for singleton pregnancies. The waveforms from both uterine arteries were also evaluated to exclude placental insufficiency. Additionally the blood flow through the AV valves was measured to exclude or confirm its regurgitation. Postnatally the hemoglobin difference was evaluated if available and compared with sonographic findings.

Results. In all cases inter-twin difference in abdominal circumference was greater than $18 \mathrm{~mm}$ and inter-twin weight difference of more than $15 \%$. We observed polyhydramnios/oligohydramnios in all twin pregnancies.

It has been found decreased PI in middle cerebral artery in larger fetus (recipient) in all our cases (comparing to single pregnancy). PI values for this vessel in smaller fetuses were within normal range (for single pregnancy). PI values in umbilical arteries of recipients were abnormal (increased PI or absent end-diastolic flow).

Comments. The sonographic criteria seem to be very useful in diagnosis of twin-to-twin transfusion syndrome, especially in cases where the measurement of hemoglobin level is impossible. Doppler blood flow velocimetry in fetal vessels helps to explain the changes in fetal hemodynamics in TTTS.

Key words: Twin-to-twin transfusion (TTTS) syndrome, Prenatal ultrasound, Doppler blood flow velocimetry 


\section{INTRODUCTION}

Twin-to-twin transfusion syndrome (TTTS) is rather rare but represents an important complication in twin pregnancies with serious perinatal implications. It results from shunting of blood from one twin to the other through placental vascular anastomoses. It has been shown that vascular anastomoses are widely present in monochorionic placentas. The anastomoses have been also found in dichorionic placentas but its incidence is very low $[5,25,26]$. Vascular anastomoses may be superficial, deep or a combination of both of them [7]. The size, direction, number and type of anastomoses all influence the degree of dissimilarity of onset and severity between monozygotic twins with TTTS. The youngest example of this syndrome has been described in a pair of aborted twins of 10 weeks gestation [6]. It has been described acute and chronic form of twin-to-twin transfusion syndrome [23, 32].

In the past, the diagnosis of the syndrome was made only after delivery of the affected twins and careful examination of the placenta. TTTS was usually diagnosed by the discovery of a hemoglobin difference $>5 \mathrm{~g} / \mathrm{dL}$ between twins [25] and a birth weight difference $>20 \%$ [32]. Currently, modern technologies allow prenatal diagnosis and also potential therapy. Wittmann et al. [33] and Brennan et al. [9] provided the sonographic criteria for TTTS. Wittmann pointed on the striking discrepancy in the sizes of the twins and in the hydramnios. Brennan suggested additional criteria included the same sex, disparity in size or in the number of umbilical vessels, single placenta showing divergent echogenicity of the cotyledons supplying the two cords, the evidence of hydrops in either twin or congestive cardiac failure in the recipient. Blickstein [7] in 1990 presented a new composite definition of this syndrome. It includes the following criteria: minor criteria: 1) sonographic signs (inter-twin differences in abdominal circumference greater than $18 \mathrm{~mm}$, polyhydramnios/oligohydramnios, and signs of monozygosity), 2) Doppler velocimetry of the umbilical arteries (inter-twin difference in systolic/diastolic ratios above 0,4 ); major criteria: 1 ) demonstration of transplacental vascular shunt, 2) inter-twin birth weight difference of $15 \%$ or more, 3) inter-twin hemoglobin difference of $5 \mathrm{~g} / \mathrm{dL}$. Composite diagnosis of TTTS requires two major criteria or one major and one minor criterion. Considering the observation of other authors [7,13] and many pitfalls in neonatal diagnosis, a new set of criteria is needed.

The aim of this study was to show the diagnostic possibilities of ultrasound in TTTS, to demonstrate its usefulness in cases of hemoglobin difference $<5 \mathrm{~g} / \mathrm{dL}$ in infants as well as in cases complicated by intrauterine death one or both twins.

\section{MATERIAL AND METHOD}

Between february 1997 and december 1998 we observed 4 twin pairs between 25 and 34 week of gestation who manifested signs of TTTS. The diagnosis was mainly based on sonographic criteria. The patients were transferred to the Department of Perinatology and Gynecology in Poznań (a tertiary referral center) for antenatal care from other hospitals.

Ultrasonographic examinations were performed using sonographic machine (Acuson 
$128 \mathrm{XP}$ ) equipped in $3,5 / 5 \mathrm{MHz}$ transducer with pulsed and color Doppler facilities. In all fetuses congenital malformation were excluded.

The fetal weight was calculated on the basis of fetal biparietal diameter (BPD), head circumference (HC), abdominal circumference (AC) and femur length (FL). The inter-twin abdominal circumference difference and the inter-twin fetal weight difference, expressed as a percentage of a larger fetus, were calculated. The amniotic fluid volume was evaluated measuring a maximal vertical amniotic fluid pocket in both amniotic cavities.

The assessment of placenta was a next step of examination. It included: number of placentas, localization and echogenicity of placenta, size of umbilical cord (edema) and number of umbilical vessels.

The attention was also paid on a presence or absence of fetal edema, ascites, pleural or pericardial effusion, a distended urinary bladder, the same gender.

Color flow mapping and pulsed Doppler velocimetry (Acuson $128 \mathrm{XP}$ ) were performed at the time of diagnosis. For each fetus, flow velocity waveforms were recorded from the umbilical cord artery, middle cerebral artery, AV valves and additionally from both uterine arteries. All records were made in the absence of fetal gross body and breathing movements. The rule was to achieve a low angle of insonation. It was not always possible for technical problems resulting from polyhydramnios or oligohydramnios. Three consecutive waveforms of satisfactory quality were used for calculation of Doppler indices.

Postnatally, the pathomorphological examination of placentas was performed to confirm the existence of vascular anastomoses.

\section{RESULTS}

\section{Case N. 1}

The multigravida in multiple pregnancy at 26 week of gestation was admitted to our hospital for antenatal care. The discordant growth of fetuses and the signs of hydrops in one twin were diagnosed. This twin, at the examination, presented features of generalized edema (Fig. 1), ascites (Fig. 2), pericardial effusion and biventricular hypertrophy (Fig. 3 ), distended urinary bladder and edematic umbilical cord. The maximal vertical amniotic fluid pocket (MAP) was $11 \mathrm{~cm}$ pointing on polyhydramnios. The biometry, including the differences in abdominal circumferences and in fetal weights expressed as a percentage of the larger fetus, is shown in Table 1.

Flow velocity waveforms from umbilical vessels showed an absent end-diastolic blood flow in umbilical artery and pulsation in umbilical vein (Fig. 4). There were signs of centralization in central nervous system (decreased PI in middle cerebral artery) (Fig. 5). It has been also observed changes in venous system such as an increased reversed flow in inferior vena cava and reversed flow in ductus venosus suggesting the insufficiency of the right heart (ventricle) (Fig. 6). Additionally Doppler echocardiography has demonstrated regurgitation of AV valves (mitral and tricuspid regurgitation).

The donor was significantly smaller (Tab. 1) surrounded by low amniotic fluid vol- 


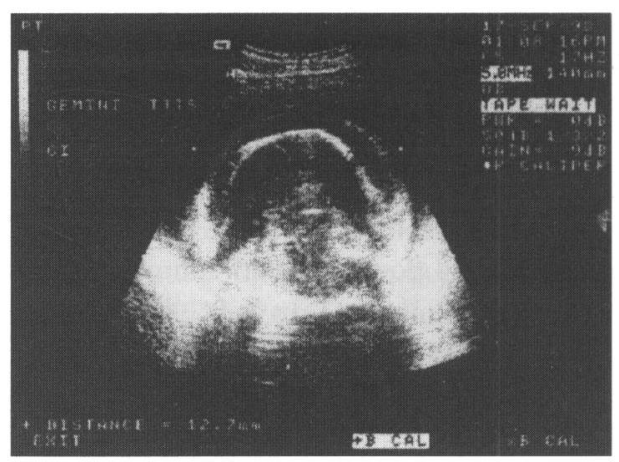

Fig. 1 - The transverse scan of the head of the larger twin in case No 1 (skin edema).

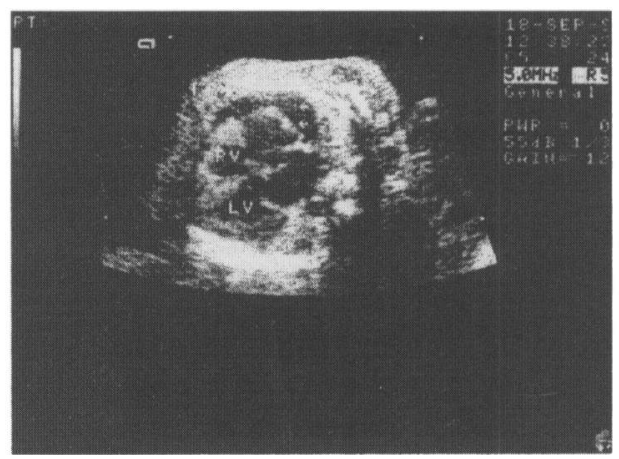

Fig. 3 - Pericardial effusion and myocardial hypertrophy of fetal heart (the hydropic fetus in case 1).

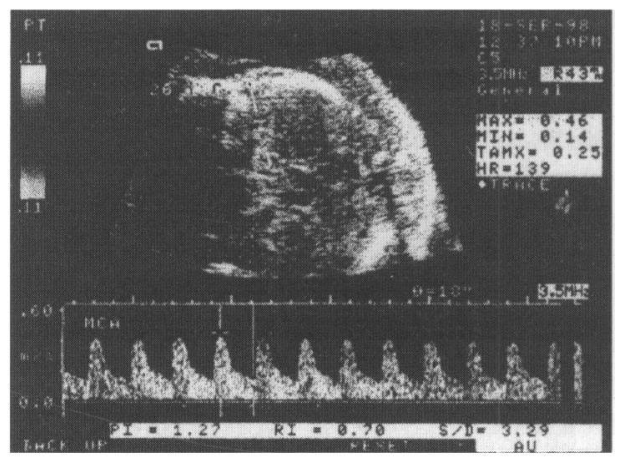

Fig. 5 - The decreased PI value in middle cerebral artery pointing on vasodilatation in central nervous system (case 1 - the larger twin).

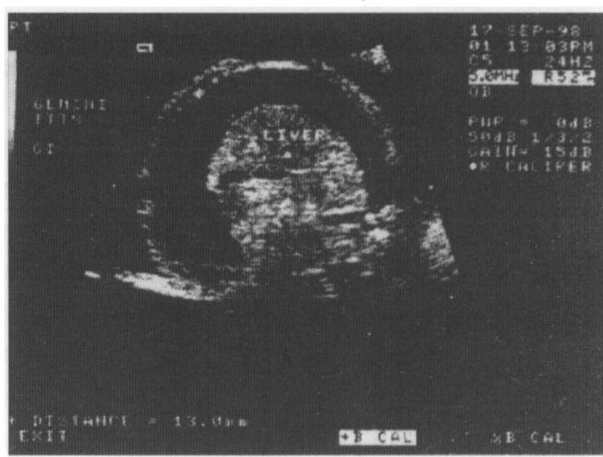

Fig. 2 - The huge amount of free fluid (ascites) in abdominal cavity of the larger fetus (case 1).

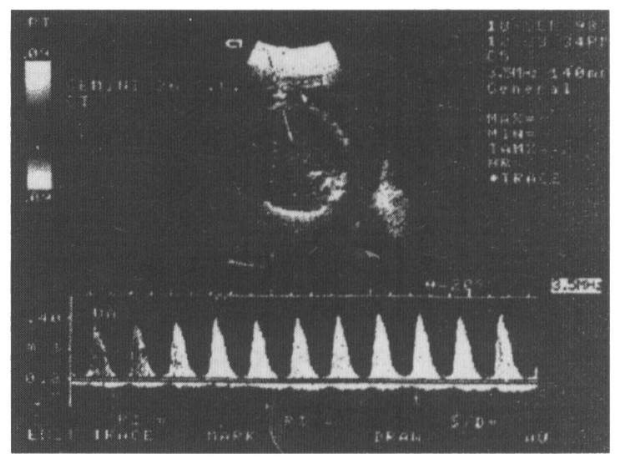

Fig. 4 - Absent-end diastolic blood flow in umbilical artery of hydropic fetus (case 1).

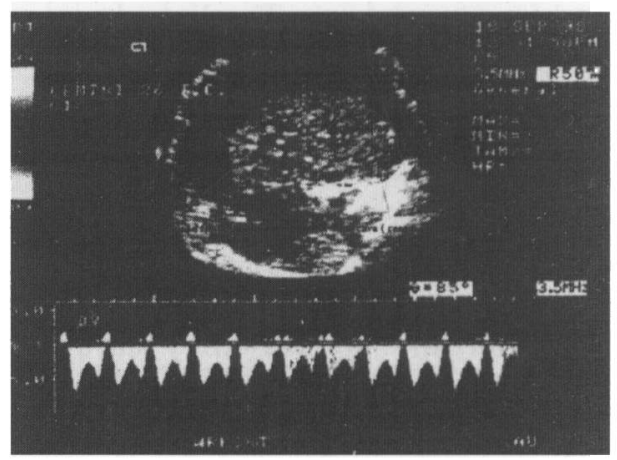

Fig. 6 - Reversed end-diastolic blood flow in ductus venosus (case 1 - the larger twin). 
Table 1 - Ultrasonographic findings, hemoglobin level and outcome in recipient and donor twins

\begin{tabular}{|c|c|c|c|c|c|c|c|c|}
\hline & \multicolumn{2}{|c|}{ case 1} & \multicolumn{2}{|c|}{ case 2} & \multicolumn{2}{|c|}{ case 3} & \multicolumn{2}{|c|}{ case 4} \\
\hline & $r$ & $\mathrm{~d}$ & $r$ & $d$ & $\mathrm{r}$ & d & $\mathrm{r}$ & $\mathrm{d}$ \\
\hline Gestational age (weeks) & \multicolumn{2}{|c|}{26} & \multicolumn{2}{|c|}{34} & \multicolumn{2}{|c|}{28} & \multicolumn{2}{|c|}{25} \\
\hline Fetal weight $(\mathrm{g})$ & 1390 & 810 & 1910 & 1390 & 1160 & 818 & 688 & 515 \\
\hline Growth discordance $(\%)$ & \multicolumn{2}{|c|}{42} & \multicolumn{2}{|c|}{27} & \multicolumn{2}{|c|}{29} & \multicolumn{2}{|c|}{25} \\
\hline $\begin{array}{l}\text { Abdominal } \\
\text { circumference }(\mathrm{mm})\end{array}$ & 278 & 208 & 283 & 250 & 233 & 209 & 199 & 177 \\
\hline Discordance $(\mathrm{mm})$ & \multicolumn{2}{|c|}{70} & \multicolumn{2}{|c|}{33} & \multicolumn{2}{|c|}{24} & \multicolumn{2}{|c|}{22} \\
\hline \multicolumn{9}{|l|}{ Other signs: } \\
\hline - hydrops & + & - & - & - & - & - & - & - \\
\hline - edema & + & - & - & - & - & - & - & - \\
\hline - pericardial effusion & + & - & - & - & - & - & - & - \\
\hline - ascites & + & - & - & - & - & - & - & - \\
\hline Polydramnios - MAP $(\mathrm{cm})$ & 11 & - & 10 & - & 9 & - & 10 & - \\
\hline Oligohydramnios - MAP $(\mathrm{cm})$ & - & 2 & - & 1 & - & 1 & - & 2 \\
\hline Birth weight (g) & 1420 & 1090 & 1960 & 1410 & 1230 & 890 & 690 & 510 \\
\hline Growth discordance $(\%)$ & \multicolumn{2}{|c|}{23} & \multicolumn{2}{|c|}{28} & \multicolumn{2}{|c|}{27} & \multicolumn{2}{|c|}{26} \\
\hline Hemoglobin level $(\mathrm{g} / \mathrm{dL})$ & - & 16,0 & 22,0 & 18,0 & 24,0 & 20,5 & - & - \\
\hline \multicolumn{9}{|l|}{ Hemoglobin level } \\
\hline Discrepancy $>5 \mathrm{~g} / \mathrm{dL}$ & \multicolumn{2}{|c|}{-} & \multicolumn{2}{|c|}{4,0} & \multicolumn{2}{|c|}{3,5} & \multicolumn{2}{|c|}{-} \\
\hline
\end{tabular}

$\mathbf{r}$-recipient; $\mathrm{d}$-donor; $\quad$ MAP-maximal amniotic fluid packet

Table 2 - Doppler blood flow velocimetry results

\begin{tabular}{|c|c|c|c|c|c|c|c|c|}
\hline & \multicolumn{2}{|c|}{ case 1} & \multicolumn{2}{|c|}{ case 2} & \multicolumn{2}{|c|}{ case 3} & \multicolumn{2}{|c|}{ case 4} \\
\hline & $\mathbf{r}$ & d & r & d & $r$ & $d$ & r & $\mathrm{d}$ \\
\hline Gestational age (weeks) & \multicolumn{2}{|c|}{26} & \multicolumn{2}{|c|}{34} & \multicolumn{2}{|c|}{28} & \multicolumn{2}{|c|}{25} \\
\hline $\mathrm{UA}(\mathrm{PI})$ & ARED & 1,02 & 2,03 & 0,92 & 1,89 & 1,38 & 1,99 & 1,56 \\
\hline UV pulsation & $\mathrm{Y}$ & $\mathrm{N}$ & $\mathrm{Y}$ & $\mathbf{N}$ & $\mathbf{N}$ & $\mathrm{N}$ & $\mathrm{N}$ & $N$ \\
\hline $\operatorname{MCA}(\mathrm{PI})$ & $\mathbf{I}, 2 \mathrm{I}$ & 2,21 & 1,18 & 1,89 & 1,12 & 1,92 & - & 1,42 \\
\hline TV regurgitation & $\mathrm{Y}$ & $N$ & $\mathrm{~N}$ & $\mathrm{~N}$ & $\mathrm{~N}$ & $\mathrm{~N}$ & $\mathrm{~N}$ & $\mathrm{~N}$ \\
\hline RUA (PI) & \multicolumn{2}{|c|}{0,78} & \multicolumn{2}{|c|}{0,85} & \multicolumn{2}{|c|}{1,02} & \multicolumn{2}{|c|}{0,89} \\
\hline LUA (PI) & \multicolumn{2}{|c|}{0,99} & \multicolumn{2}{|c|}{0,65} & \multicolumn{2}{|c|}{0,99} & \multicolumn{2}{|c|}{1,12} \\
\hline
\end{tabular}

$\mathrm{r}$-recipient; $\mathrm{d}$-donor; UA - umbilical artery; UV-umbilical vein; $\mathrm{MCA}$ - middle cerebral artery; TV regurgitation - tricuspid valve regurgitation; RUA - right uterine artery; LUA - left uterine artery; $\mathrm{PI}$ - pulsatility index; . Y - yes; $\quad \mathrm{N}$ - no; ARED - absent end-diastolic flow 
ume (MAP $=2 \mathrm{~cm}$ ). Doppler blood flow velocimetry in umbilical vessels and middle cerebral artery was normal. Doppler blood flow velocimetry from both uterine arteries was within physiological ranges.

The sonographic assessment confirmed the same male gender of fetuses and a single placenta of different echogenicity on the posterior uterine wall.

The mather did not except any proposed form of treatment in utero. The recipient died in utero seven days after the first sonographic examination. The pregnant patient delivered by cesarean section (signs of fetal distress) at 30 week of gestation and gave birth to one alive child (T I male, birth weight $1090 \mathrm{~g}$, Ap 7; T II male, birth weight 1420 , Ap 0; birth weight difference of $23 \%$ ). The hemoglobin level in T I was $16 \mathrm{~g} / \mathrm{dL}$.

\section{Case N. 2}

The primipara at 29 week of gestation was admitted to our center because of inter-twin weight difference. The sonographic evaluation showed a single placenta located on the anterior uterine wall of different echogenicity. It has been found a difference in abdominal circumference of $23 \mathrm{~mm}$ and growth discordance of $20 \%$. Both female fetuses presented no structural defects. The amniotic fluid volume in both sacks was comparable. Doppler blood flow velocimetry in umbilical vessels, middle cerebral arteries and uterine arteries was normal. Ultrasonographic monitoring was carried on every week.

The differences in abdominal circumference and fetal size increased, reaching 33 $\mathrm{mm}$ and $27 \%$ at 34 week of gestation (Tab. 1). The umbilical artery PI value in the recipient increased up to 2,03 (in donor 0,92) and inter-twin difference in S/D ratios was 0,5 . PI value in middle cerebral artery of the recipient was decreased $(1,18)$ and within normal range $(1,89)$ in the donor (Tab. 2). The shape of waveforms and PI values in both uterine arteries were normal. Polyhydramnios developed in one sack (MAP $=10 \mathrm{~cm}$ ), in other oligohydramnios (MAP $=1 \mathrm{~cm}$ ). The signs of fetal distress appeared in CTG recording of recipient fetus. The pregnant woman delivered by cesarean section two alive female twins (birth weight $1960 \mathrm{~g}$ and $1410 \mathrm{~g}$; Apgar score in 5 minute 6 and 8; Hb $22,0 \mathrm{~g} / \mathrm{dL}$ and $18,0 \mathrm{~g} / \mathrm{dL}$; birth weight difference of $28 \%$ ).

\section{Case N. 3}

The primipara at 28 week of gestation was admitted to the hospital. Ultrasound examination confirmed twin pregnancy with inter-twin growth discrepancy. It has been found the difference in abdominal circumference $24 \mathrm{~mm}$ and fetal growth discrepancy of $29 \%$. The single placenta was located on the posterior uterine wall. Both male fetuses presented no structural abnormalities. The maximal vertical amniotic fluid pocket of larger fetus was 9 $\mathrm{cm}$ and of smaller $1 \mathrm{~cm}$.

The larger fetus showed an increased PI value (comparing to single pregnancies) in umbilical artery $(1,89)$ and decreased in middle cerebral artery $(1,12)$. The smaller fetus (presumably donor) showed PI values as in umbilical artery $(1,38)$ as middle cerebral artery $(1,92)$ within normal range for single pregnancy. There were no signs of pulsation in umbilical vein and AV regurgitation in both fetuses. The shape of waveforms and PI values in both uterine arteries were normal (Tab. 2).

However, CTG of the larger fetus showed variable decelerations and narrow oscilla- 
tion. The patients delivered by cesarean section at 28 week of gestation giving birth to two male twins (T I $1230 \mathrm{~g}$, Ap 5; T II $890 \mathrm{~g}$, Ap 6). The birth weight difference was $27 \%$. The hemoglobin level in both twins was measured reaching $24,0 \mathrm{~g} / \mathrm{dL}$ and 20,5 $\mathrm{g} / \mathrm{dL}$ respectively.

\section{Case N. 4}

The multipara at 25 week of gestation was admitted to the hospital according to huge polyhyramnios. By ultrasound a twin pregnancy was diagnosed. It has been found a single placenta on the anterior uterine wall, polyhydramnios in one sack (MAP $=20 \mathrm{~cm}$ ) and oligohydramnios in second sack $(M A P=2 \mathrm{~cm}$ ). The patient complained of abdominal pain and increasing dyspnea. The fetal growth discrepancy (fetal weight difference of $25 \%$, fetal abdominal circumference of $22 \mathrm{~mm}$ ) was observed. It has been noticed no fetal abnormalities.

Doppler blood flow velocimetry showed an increased PI value $(1,99)$ (comparing to single pregnancies) in umbilical artery of larger fetus (probably recipient) and PI value of the smaller one $(1,56)$ was within the normal range for single pregnancies. The PI obtained from middle cerebral artery (MCA) was 1, 42 for smaller fetus (within normal range for single pregnancies). The signal from MCA of larger fetus was undetectable (huge polyhydramnios). In has not been observed any signs of umbilical vein pulsation and AV regurgitation in both fetuses. Doppler blood flow velocimetry in both uterine arteries was normal (Tab. 2).

Regarding to huge polyhydramnios a catheter into amniotic cavity was placed. During two successive days 1,5 1 amniotic fluid was removed. In the third day of amnioreduction signs of placental abruption appeared and cesarean section was performed. Unfortunately both fetuses died in utero (T I female, $690 \mathrm{~g}$, Ap 0; T II female, $510 \mathrm{~g}$, Ap 0 ; birth weight difference of $26 \%$ ). During the operation the total placental abruption was confirmed.

\section{DISCUSSION}

Twin-to-twin transfusion syndrome does not exist without a transplacental transfusion. Cross-circulation may be demonstrated in monochorionic as well as dichorionic placentas [26]. The occurrence of TTTS in dichorionic placentas is very rare therefore it seems to be safe to conclude that feto-fetal transfusion is typical for monochorionic-monozygotic twins [6]. The pathomorphological background concerns vascular anastomoses or shunts between the fetal circulation that are observed in the majority of monochorionic placentas [4]. Vascular anastomoses are probably formed during the early angiogenetic stages of the placenta, but may become functional in any stage of pregnancy, during labor and delivery, or not at all. These anastomoses may cease to function after the death of one fetus. Furthermore, the shunts may function insidiously, producing chronic transfusion, or it may open suddenly, resulting in acute and often fatal transfusion. In a unique situation, a large arterio-arterial shunt may give rise to reversed flow, causing an acardiac fetus whose circulation is supported by the normal donor twin [30]. 


\section{M. Ropacka et al.}

Twin-to-twin transfusion syndrome has traditionally been diagnosed after birth, confirmed by the hemoglobin difference $>5 \mathrm{~g} / \mathrm{dL}[25]$ and birth weight differences (more than $20 \%$ ). These criteria became a background of conflict between the neonatologists and obstetricians who diagnosed this syndrome based also on other features such as sonographic signs. Danskin and Neilson [13] recently reevaluated the diagnostic criteria of the syndrome. Intertwin hemoglobin differences of more than $5 \mathrm{~g} / \mathrm{dL}$ and birth weight differences (more than 20\%) were found in monochorionic and dichorionic twinning at similar rates. The largest hemoglobin differences were found in dichorionic pregnancies. Because placental anastomoses are extremely rare in fused dichorionic placentas [26], it is unlikely that TTTS occurred in dichorionic placentas. The authors concluded that a difference in hemoglobin concentration is not in itself sufficient to establish a diagnosis of twin-to-twin transfusion syndrome. It has also been noticed that a birth weight difference $>20 \%$ occurred no more commonly in monochorionic pregnancies than in dichorionic pregnancies. In addition of the four pregnancies in which hemoglobin difference $>5$ $\mathrm{g} / \mathrm{dL}$ and a birth weight difference $>20 \%$ coexisted, only one had a monochorionic placenta. In this pregnancy the heavier twin had the higher hemoglobin value, whereas in three dichorionic pregnancies the lighter twin had the higher hemoglobin value. These presumably represent growth retardation in association with polycytemia [13].

This preliminary study included four pairs of twins. In two cases the hemoglobin differences were $<5 \mathrm{~g} / \mathrm{dL}$ and in two remaining cases it was impossible to evaluate this difference (intruterine death). On the base of sonographic criteria presented by Blickstein [7] we were able to diagnose twin-to-twin transfusion syndrome. In all cases the twins presented divergent fetal size. It has been found the difference in abdominal circumference $>20 \mathrm{~mm}$ and fetal weight of more than $20 \%$. Currently, the most accurate diagnoses are being made by comparing abdominal rather than head circumference of twins $[8,31]$. A cutoff value of $20 \mathrm{~mm}$ difference in abdominal circumference discriminated between growth discordance of more or less than 20\% [31].

All twin pairs presented polyhydramnios/oligohydramnios. Chescheir and Seeds [12] described monochorionic placentas and TTTS in six of the seven twin pregnancies with signs of polyhydramnios/oligohydramnios. An increased fetal micturition due to the volume overload with possible congestive cardiovascular failure seems to be a reason of polyhydramnios development $[2,11,22]$. A "stuck twin", an important sonographic sign, has been also seen in many cases of TTTS [10]. In this study this sign was seen in one case (No 3). In case No 1 it has been noticed the enlarged, edematic umbilical cord of the recipient. This feature was also observed by Abraham [1], but the validity of it has not been established in large groups.

Recently, it has been proved that erythropoetic changes, reversed intrapartum shunts, and untimely umbilical cord clamping of either donor or recipient [23] may result in false-positive and false-negative records when the diagnosis is based on hemoglobin disparity alone. However, the second basic criterion of TTTS, that means inter-twin birth weight differences more than $20 \%$ could also be controversial. Pitfalls may be encountered when the transfusion occurs during labor or when hydropic changes occur and obscure the real inter-twin size disparity. Additionally, there are cases of a donor being larger then the recipient, especially in the lower range of birth weight discordance [7]. Therefore a modern obstetrics includes Doppler blood flow velocimetry to the diagnosis and monitoring of TTTS. Doppler measurements may help to differentiate between 
genetically small twins or placental insufficiency $[3,14,18,19,24,27]$. Some studies excluded all cases of placental insufficiency. All pregnant patients demonstrated normal shape of uterine artery waveforms and PI values were within physiological ranges. However, the usefulness of Doppler measurements in TTTS is limited. Doppler assessment of pregnancies help in the prediction of outcome or in the distinction of those pregnancies that are best managed conservatively or by interventions [21]. A special meaning may have Doppler echocardiography demonstrating regurgitation of AV valves. The recipient fetus may manifest the tricuspid or even mitral regurgitation as a result of an increase in cardiac pre-and after load. Semiquantitative evaluation of the severity of AV valve regurgitation seems to be helpful parameter to follow the course of TTTS [16]. It has been also noticed that only in the presence of holosystolic regurgitation, hydrops may occur at various time intervals [17]. In our study the holosystolic regurgitation was observed in case No 1. The recipient at the moment of the first examination generalized edema, ascites, pericardial effusion and myometrial hypertrophy presented. The fetus manifested also signs of arterial hypertension, increased resistance to blood flow and features of right and left heart insufficiency resulting in intrauterine death. The remaining fetuses from this study did not manifest any signs of AV valves regurgitation. But two of them also died in utero. The reason of those deaths was the placental abruption (case No 4).

In the last three cases it has been noticed an increased resistance to flow in the umbilical artery in recipient. In case No 1 the recipient manifested the absent end-diastolic flow in umbilical artery which is widely known as a serious sign of fetal distress and linked to a very poor prognosis. The studies concerning the measurements of resistance to flow in the umbilical arteries and the results are very controversial. Giles et al. [20] found concordant values in both twins and did not observe significantly abnormal waveforms. Yamada et al. [34] found the higher resistance in donor, but the values were still within the normal range. Hecher et al. [21] observed an increase in resistance to flow in the umbilical artery in both the donor and the recipient. These findings may be explained by data that suggest the primary maldevelopment of the placenta of the donor $[28,29]$. The donor may manifest signs of severe uteroplacental insufficiency with additional features of chronic hemorrhage and hypowolemia. The recipient may also show the resistance to flow due to compression of the cord as a result of polyhydramnios [15] or due to placental edema, the result of hyperwolemia-related heart failure [21].

Doppler measurements in middle cerebral artery of the donors in all cases suggest the absence of redistribution in the fetal circulation. Decreased PI values in the middle cerebral artery were observed in case No 1, 2 and 3. In case No 4 we could not measure it because of severe polyhydramnios. Decreased PI values in the two first recipients may be the consequence of hyperwolemia-related congestive heart failure or may signify vasodilatation in response to heart failure-related hypoxemia [21].

Doppler findings in the circulation of the donor are better explained by hypowolemia than anemia and hypoxemia. In the recipient, the findings can be explained partly by hyperwolemia and congestive heart failure. 


\section{REFERENCES}

1. Abraham JM (1967): Intrauterine feto-fetal transfusion syndrome. Clinical observation and speculation on pathogenesis. Clin Pediatr 6: 405-10.

2. Achiron R, Rosen N, Zakut H (1987): Patophysiologic mechanism of hydramnios development in twin transfusion syndrome. A case report. J Reprod Med 32: 305-8.

3. Arabin B, Jimenez E, Saling E (1987): Die Bedeutung von Doppler-Blutflussmessung bei Geminigraviditat. Z Geburtsh Perinat 191: 99-104.

4. Bebbington MW, Wittmann BK (1989): Fetal transfusion syndrome: antenatal factors predicting fetal outcome. Am J Obstet Gynecol 160: 913-15.

5. Bernischke K (1961): Twin placenta in perinatal mortality. NY State J Med 61: 1499-508.

6. Benirschke K, Chung KK (1973): Multiple pregnancy. New Engl Med J 288: 1276-84.

7. Blickstein I (1990): The twin-twin transfusion syndrome. Obstet Gynecol 76: 714-21.

8. Blickstein I, Friedman A, Caspi B, Lancet M (1989): Ultrasonic prediction of growth discordance by intertwin difference in abdominal circumference. Int J Gynecol Obstet 29: 121-4.

9. Brennan JN, Divan RV, Rosen MG, Bellon EM (1982): Fetofetal transfusion syndrome: Prenatal ultrasonographic diagnosis. Radiology 143: 535-6.

10. Brown DL, Benson CB, Driscoll SG, Doubilet PM (1989): Twin-twin transfusion syndrome: Sonographic findings. Radiology 170: 61-3.

11. Campbell S, Wladimiroff JW, Dewhurst DI (1973): The antenatal measurement of fetal urinary production. J Obstet Gynaecol Br Commonw 80: 680-6.

12. Chescheir NC, Seeds JW (1988): Polyhydramnios and oligohydramnios in twin gestation. Obstet Gynecol 71: 882-4.

13. Danskin FH, Neilson JP (1989): Twin-to-twin transfusion syndrome: What are appropriate diagnostic criteria? A J Obstet Gynecol 161: 365-9.

14. Farmakides G, Schulman H, Saldana LR, Bracero LA, Fleischer A, Rochelson B (1985): Surveillance of twin pregnancy with umbilical velocimetry. Am J Obstet Gynecol 153: 789-92.

15. Fries MH, Goldstein RB, Kilpatrick SJ (1993): The role of velamentous cord insertion in the etiology of twin-twin transfusion syndrome. Obstet Gynecol 81: 569-74.

16. Gembruch U, Arabin B (1994): Twin to twin transfusion syndrome. In: van Geijn HP, Copray FJA (Ed): A critical appraisal of fetal surveillance. Elsevier Science BA, chapter 22: 169-79.

17. Gembruch U, Redel DA, Bald R, Hansman M (1993): Longitudinal study in 18 cases of fetal supraventricular tachycardia: Doppler echocardiographic findings and pathophysiologic implications. Am Heart J 125: 1290-1301.

18. Giles WB, Trudinger B, Cook CM (1985): Fetal umbilical artery flow velocity-time wave forms in twin pregnancy. Br J Obstet Gynaecol 92: 490-97.

19. Giles WB, Trudinger BJ, Cook CM, Connelly A (1988): Umbilical artery flow velocity wave forms and twin pregnancy outcome. Obstet Gynecol 72: 984-97.

20. Giles WB, Trudinger BJ, Cook CM (1990): Doppler umbilical artery studies in twin-twin transfusion syndrome. Obstet Gynecol 76: 1097-1102.

21. Hecher K, Ville Y, Nicolaides KH (1995): Fetal arterial Doppler studies in twin-twin transfusion syndrome. J Ultrasound Med 14: 101-108.

22. Kirshon B (1989): Fetal urine output in hydramnios. Obstet Gynecol 73: 240-2.

23. Klebe JG, Ingomar CJ (1972): The fetoplacental circulation during parturition illustrated by the interfetal transfusion syndrome. Pediatrics 49: 112-6.

24. Nimrod C, Davies D, Harder J, Dempster C, Dodd G, Mcdicken N, Nicholson S (1987): Doppler ultrasound prediction of fetal outcome in twin pregnancies. Am J Obstet Gynecol 156: 402-06.

25. Rausen AR, Seki M, Strauss L (1965): Twin transfusion syndrome. J Pediatr 66: 613-28.

26. Robertson EG, Neer KJ (1983): Placental injection studies in twin gestation. Am J Obstet Gynecol 147: 170-4.

27. Saldana LR, Eads MC, Schaefer TR (1985): Umbilical blood wave forms in fetal surveillance of twins. Am J Obstet Gynecol 153: 789-92. 
28. Saunders NJ, Snijders RJM, Nicolaides KH (1991): Twin-twin transfusion syndrome in the second trimester is associated with small intertwin hemoglobin differences. Fetal Diagn Ther 6: 34-7.

29. Saunders NJ, Snijders RJM, Nicolaides KH (1992): Therapeutic amniocentesis in twin-twin transfusion syndrome appearing in the second trimester of pregnancy. Am J Obstet Gynecol 166: 820-6.

30. Schinzel AA, Smith DW, Miller JR (1979): Monozygotic twinning and structural defects. J Pediatr 95: 921-30.

31. Storlazzi E, Vintzileos AM, Campbell WA, Nochimson DJ, Weinbaum PJ (1987): Ultrasonic diagnosis of discordant fetal growth in twin gestations. Obstet Gynecol 69: 363-7.

32. Tan KL, Tan R, Tan SH, Tan AM (1979): The twin transfusion syndrome. Clin Pediatr 18: 114-4.

33. Wittmann BK, Baldwin VJ, Nichol B (1981): Antenatal diagnosis of twin transfusion syndrome by ultrasound. Obstet Gynecol 58: 123-6.

34. Yamada A, Kasugai M, Ohno (1991): Antenatal diagnosis of twin-twin transfusion syndrome by Doppler ultrasound. Obstet Gynecol 78: 1058-61.

Correspondence: Mariola Ropacka, Klinika Perinatologii i Ginekologii, Ginekologiczno-Położniczy Szpital Kliniczny Akademii Medycznej, 60-535 Poznań, ul. Polna 33, Polska. 